Research Paper

\title{
Inhibition of DUSP6 sensitizes ovarian cancer cells to chemotherapeutic agents via regulation of ERK signaling
} response genes

\author{
Nicole E. James ${ }^{1,3}$, Lindsey Beffa ${ }^{1}$, Matthew T. Oliver ${ }^{1}$, Ashley D. Borgstadt ${ }^{1}$, \\ Jenna B. Emerson', Clinton O. Chichester ${ }^{3}$, Naohiro Yano ${ }^{2}$, Richard N. Freiman', \\ Paul A. DiSilvestro' and Jennifer R. Ribeiro' \\ ${ }^{1}$ Women and Infants Hospital, Department of Obstetrics and Gynecology, Program in Women's Oncology, Providence, RI, \\ USA \\ ${ }^{2}$ Department of Surgery, Roger Williams Medical Center, Providence, RI, USA \\ ${ }^{3}$ Department of Pharmacy, University of Rhode Island, Kingston, RI, USA \\ ${ }^{4}$ Department of Molecular and Cell Biology and Biochemistry, Brown University, Providence, RI, USA \\ Correspondence to: Jennifer R. Ribeiro, email: Jrribeiro@wihri.org \\ Keywords: DUSP6; HE4; ovarian cancer; chemoresistance; ERK signaling \\ Received: November 07, $2018 \quad$ Accepted: April 14, $2019 \quad$ Published: May 21, 2019 \\ Copyright: James et al. This is an open-access article distributed under the terms of the Creative Commons Attribution License \\ 3.0 (CC BY 3.0), which permits unrestricted use, distribution, and reproduction in any medium, provided the original author and \\ source are credited.
}

\section{ABSTRACT}

Dual specificity phosphatase 6 (DUSP6) is a protein phosphatase that deactivates extracellular-signal-regulated kinase (ERK). Since the ovarian cancer biomarker human epididymis protein 4 (HE4) interacts with the ERK pathway, we sought to determine the relationship between DUSP6 and HE4 and elucidate DUSP6's role in epithelial ovarian cancer (EOC). Viability assays revealed a significant decrease in cell viability with pharmacological inhibition of DUSP6 using (E/Z)-BCI hydrochloride in ovarian cancer cells treated with carboplatin or paclitaxel, compared to treatment with either agent alone. Quantitative PCR was used to evaluate levels of ERK pathway response genes to BCI in combination with recombinant HE4 (rHE4), carboplatin, and paclitaxel. Expression of EGR1, a promoter of apoptosis, was higher in cells co-treated with BCI and paclitaxel or carboplatin than in cells treated with chemotherapeutic agents alone, while expression of the proto-oncogene c-JUN was decreased with co-treatment. The effect of BCI on the expression of these two genes opposed that of rHE4. Pathway focused quantitative PCR also revealed suppression of ERBB3 in cells co-treated with BCI plus carboplatin or paclitaxel. Finally, expression levels of DUSP6 in EOC tissue were evaluated by immunohistochemistry, revealing significantly increased levels of DUSP6 in serous EOC tissue compared to adjacent normal tissue. A positive correlation between HE4 and DUSP6 levels was determined by Spearman Rank correlation. In conclusion, DUSP6 inhibition sensitizes ovarian cancer cells to chemotherapeutic agents and alters gene expression of ERK response genes, suggesting that DUSP6 could plausibly function as a novel therapeutic target to reduce chemoresistance in EOC.

\section{INTRODUCTION}

Ovarian cancer remains the most common and deadly gynecologic cancer, responsible for 240,000 diagnoses and 152,000 deaths worldwide each year [1].
The 5-year survival rate remains at $35 \%$ [2], which is largely due to difficulty with early diagnosis, coupled with the frequency of chemoresistant recurrences [3]. A majority of epithelial ovarian cancer (EOC), the most common subtype of ovarian cancer, is initially responsive 
to chemotherapy. However, once the disease recurs, chemoresistance inevitably develops and the patient eventually will succumb to their illness [4]. Therefore, there is a need for improved diagnostic approaches, as well as novel treatment targets to combat chemoresistance.

Human epididymis protein 4 (HE4) has been established as a novel clinical biomarker for EOC. Inclusion of preoperative serum HE4 levels into the diagnostic Risk of Ovarian Malignancy Algorithm (ROMA) results in demonstrably improved specificity and sensitivity in detection and monitoring of the disease over Cancer Antigen 125 (CA 125), pelvic sonography, and menopausal status alone [5]. Research has also shown its ability to support EOC pathogenesis, including the promotion of proliferation, chemoresistance, antiestrogen resistance, adhesion, invasion, and migration [6-17]. One oncogenic pathway that has consistently been shown to interact with HE4 in several studies is the extracellular signal regulated kinase (ERK) pathway. Several reports indicate that ERK activation is enhanced with HE4 treatment or overexpression, while ERK activation is conversely reduced with HE4 knockdown $[9,15,16]$. Our lab has revealed a complex response of ERK to recombinant HE4 treatment; specifically, we have observed downregulation of ERK phosphorylation at early time points following treatment with recombinant HE4, and its upregulation at later time points [9]. However, the precise nature of HE4's interaction with the ERK pathway is not known in the context of EOC.

Dual specificity phosphatase 6 (DUSP6) is a key negative regulator of ERK signaling via dephosphorylation of ERK at serine/tyrosine residues. ERK activation upregulates gene expression of DUSP6, which promotes a negative feedback loop that suppresses ERK activation [18]. DUSP6 has differing effects on tumor progression depending on the tumor type. In pancreatic and lung cancer, DUSP6 is considered a tumor suppressor [19, 20]. However, in glioblastoma and HER-2 positive breast cancer, it is upregulated and considered oncogenic [21, 22]. In gastric cancer, DUSP6 inhibition can promote chemosensitivity [23], and it has also been characterized as a therapeutic target in acute lymphoblastic leukemia [24]. Although one ovarian cancer study suggested that DUSP6 acts as a tumor suppressor [25], the goal of the present study was to determine the potential relationship between HE4 and DUSP6 in the context of EOC.

\section{RESULTS}

\section{HE4 regulates DUSP6 levels in ovarian cancer cells}

To begin to elucidate the relationship between HE4 and DUSP6, we examined DUSP6 mRNA and protein levels in SKOV3 ovarian cancer cells overexpressing HE4 (SKOV3-C1) compared to their null vector (NV) controls, which express low levels of HE4 naturally. These assays revealed increased DUSP6 mRNA (2.15fold, $\mathrm{p}=0.008)$ and protein $(1.34$-fold, $\mathrm{p}=0.007)$ in HE4 overexpressing SKOV3 cells (Figure 1A-1B). To determine if this upregulation of DUSP6 was dependent upon continued expression of HE4, HE4 was knocked down in SKOV3-C1 cells using CRISPR/Cas9. As expected, DUSP6 levels were concomitantly reduced in two independent knockdown clones $(0.28$-fold and 0.27 fold, $p=0.015$ and $p=9.2 \times 10^{-4}$, respectively) (Figure 1C). Finally, treatment with recombinant HE4 (rHE4) at $4 \mathrm{~h}$ and 24h increased DUSP6 levels in OVCAR8 (1.68-fold, $\mathrm{p}=\mathrm{ns}, 1.37$-fold, $\mathrm{p}=\mathrm{ns})$ and SKOV3 cells $(1.57$-fold, $\mathrm{p}=\mathrm{ns}$, 2.39 -fold, $\mathrm{p}=0.032$ )(Figure 1D). These results indicate that HE4 promotes DUSP6 expression in two human ovarian cancer cell lines.

Because both DUSP6 and HE4 are involved in ERK signaling, we next examined ERK phosphorylation in response to rHE4 treatment or DUSP6 inhibition with BCI, a cell permeable allosteric inhibitor of DUSP6 MAPK phosphatase activity. Interestingly, the upregulation of phospho-ERK by rHE4 was only observed sporadically in OVCAR8 and SKOV3 cells at $24 \mathrm{~h}$ (Figure 1E). We and others have reported activation of ERK by HE4 [9, 15, 16]; specifically, we found that rHE4 suppressed phosphoERK levels at 1 and $4 \mathrm{~h}$ but increased them at 24 and $48 \mathrm{~h}$ [9]. While we did not perform a time course in the present study, the inconsistent results in this study suggest that the exact timing of phospho-ERK regulation by rHE4 may be variable.

Next, we observed an increase in phospho-ERK with BCI treatment in OVCAR8 and SKOV3 (4.03-fold and 2.45 -fold, $\mathrm{p}=\mathrm{n} / \mathrm{s}$ and $\mathrm{p}=0.043$, respectively), as would be expected if the negative regulation of ERK by DUSP6 is being suppressed (Figure 1E). Finally, co-treatment with $\mathrm{BCI}$ and rHE4 resulted in upregulation of phospho-ERK in OVCAR8 and SKOV3 (5.78-fold and 2.80-fold, $\mathrm{p}=$ $\mathrm{n} / \mathrm{s}$ and $\mathrm{p}=0.019$, respectively). In addition, there was a general positive relationship between phospho-ERK and HE4 levels, corroborating a positive relationship between activation of ERK signaling and intracellular HE4 levels (Figure 1E). We further confirmed an upregulation of HE4 by BCI at $24 \mathrm{~h}$ in OVCAR8 and SKOV3 (2.05-fold, $\mathrm{p}=.001,2.28$-fold, $\mathrm{p}=0.041$ ) (Figure 1F).

Furthermore, we determined the effect of 2-(2-Chloro-4-iodophenylamino)-N-cyclopropylmethoxy3,4-difluorobenzamide, a highly specific inhibitor of MKK1 and the ERK pathway, on DUSP6 and HE4 levels. ERK inhibition downregulated DUSP6 in OVCAR8 and SKOV3 cells, which was expected since ERK is known to positively regulate DUSP6 expression to create a negative feedback loop on ERK activation (0.69-fold and 0.42-fold, $\mathrm{p}=0.016$ and $\mathrm{p}=0.006$, respectively). In addition, a small but significant increase in HE4 levels was also observed in OVCAR8 and SKOV3 cells treated with the ERK inhibitor (1.18-fold and 1.22-fold, $\mathrm{p}=0.004$ and $\mathrm{p}=0.009$, 
respectively) (Figure 1G). The upregulation of HE4 with ERK inhibition was contrary to our expectations that ERK inhibition would suppress HE4 levels, since we observed in a previous study that cells treated with recombinant human EGF increased HE4 levels following ERK activation [14]. We hypothesize that there may be a compensatory upregulation of HE4 via other mechanisms following
ERK inhibition. Collectively, these results highlight that HE4 positively regulates DUSP6 levels in ovarian cancer cells, and both proteins regulate ERK signaling in timedependent manners. A working model for the relationship between HE4, DUSP6, and ERK signaling is outlined in Figure $1 \mathrm{H}$. Triplicate western blots from which statistics were obtained can be seen in Supplementary Figure 1.
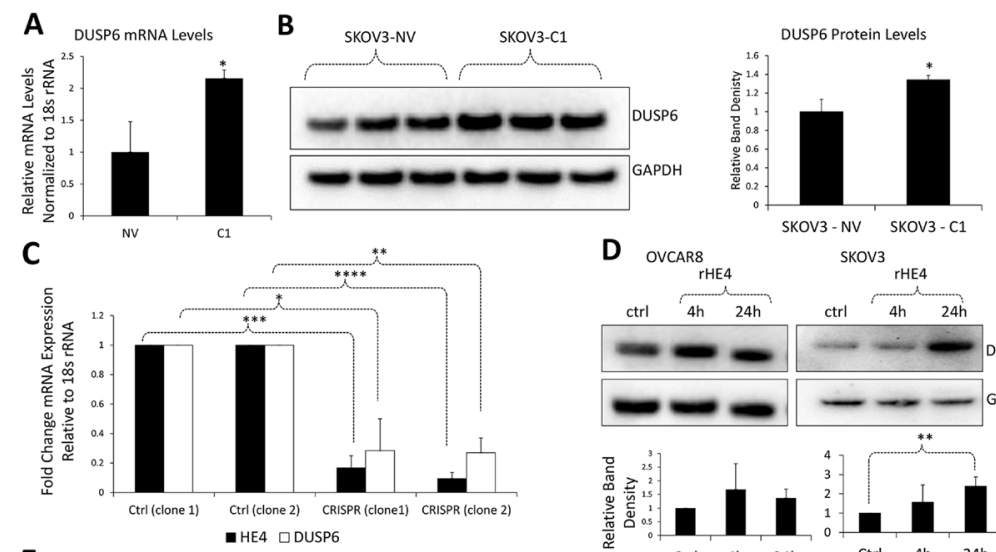

D OVCAR8

E - HE4 $\square$ DUSPG
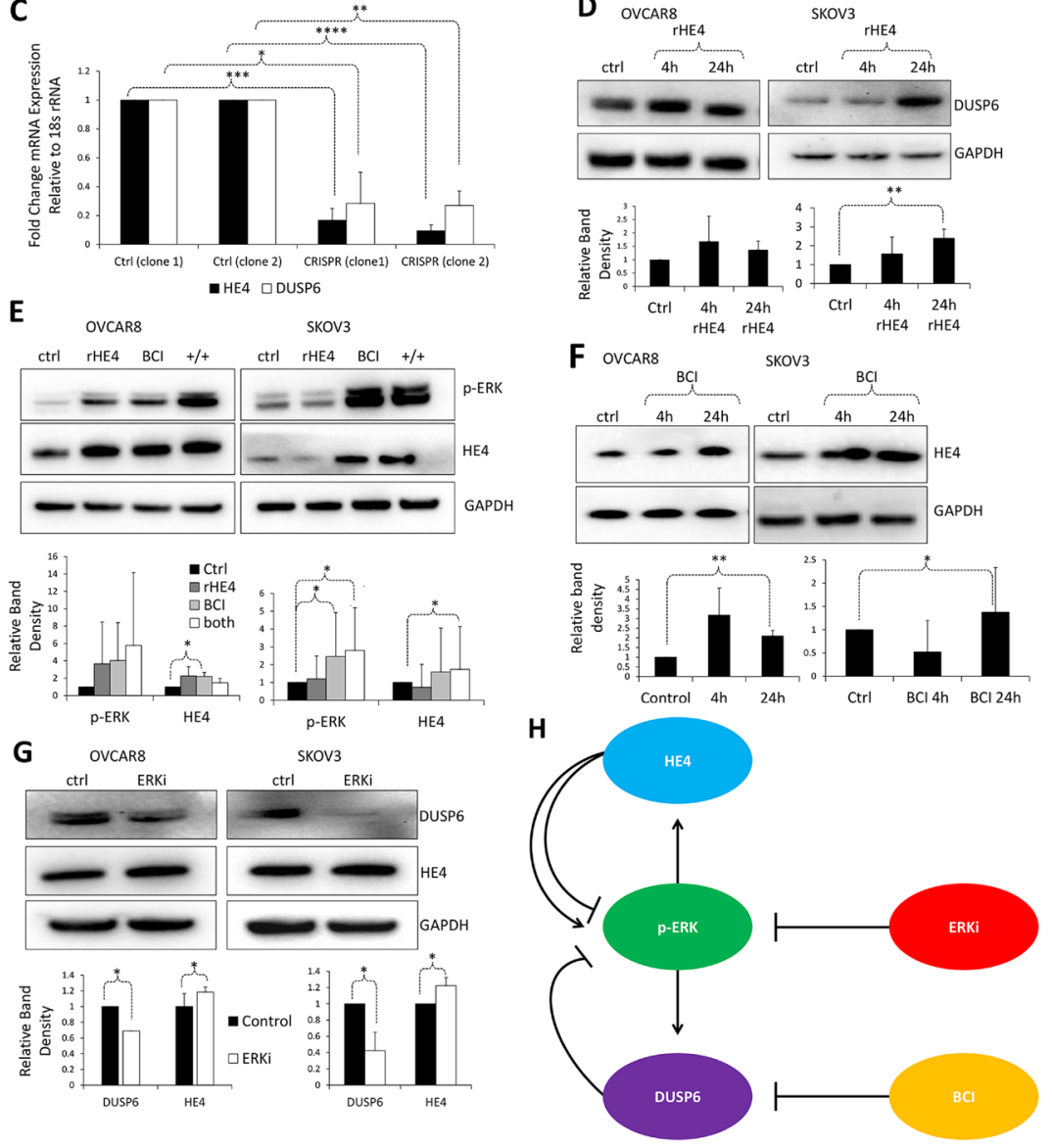

Figure 1: HE4 regulates DUSP6 levels in ovarian cancer cells (A). qPCR revealed upregulation of DUSP6 mRNA levels in SKOV3 cells overexpressing HE4 (C1) compared to null vector (NV) counterparts. (B) Western blot indicated that DUSP6 levels were upregulated in SKOV3-C1 cells compared to SKOV3-NV cells. (C) qPCR revealed downregulation of DUSP6 mRNA levels in two unique clones of SKOV3 cells with stable CRISPR-mediated HE4 knockdown. (D) Western blot showed that DUSP6 levels were upregulated with rHE4 treatment in OVCAR8 and SKOV3 cells. (E) Western blot showed that BCI treatment increased HE4 and activated ERK levels $(+/+$ refers to cells co-treated with BCI and rHE4). (F) Western blot showed that BCI increased phospho-ERK and HE4 levels in OVCAR8 and SKOV3 cells. (G) Western blot revealed that ERK inhibition downregulated DUSP6 and slightly increased HE4 levels. (H) Working model for interaction of HE4 and DUSP6 with the ERK pathway. Activated ERK is known to upregulate DUSP6 mRNA; DUSP6 then suppresses ERK activation in a negative feedback loop, while the DUSP6 inhibitor BCI reverses this effect. Also as expected, inhibition of the ERK pathway downregulated DUSP6 levels; contrary to expectations, a slight increase was seen in HE4 levels. However, phosphoERK levels appear to positively associate with HE4, suggesting a positive relationship between these proteins. This idea is reinforced by studies showing that HE4 upregulates phospho-ERK, which may occur in a time- or context-dependent manner. Error bars for all graphs represent standard deviation of $\geq 3$ biological replicates. ${ }^{*} \mathrm{p}<0.05,{ }^{* *} \mathrm{p}<0.005,{ }^{* * *} \mathrm{p}<0.0005,{ }^{* * * *} \mathrm{p}<0.00005$. 


\section{Inhibition of DUSP6 sensitizes ovarian cancer cells to chemotherapeutic drugs}

Next, we sought to determine the function of DUSP6 in ovarian cancer cells. Since HE4 is known to promote chemosresistance in vitro, and HE4 is associated with poor chemoresponse in EOC patients [9], we treated SKOV3 and OVCAR8 cells with a DUSP6 inhibitor (BCI) alone or in combination with paclitaxel or carboplatin, the standard of care chemotherapeutic agents in EOC. A dose response curve was generated to determine an optimal dose of BCI for all subsequent experiments (Supplementary Figure 2).

Treatment of cells with $3.75 \mu \mathrm{M} \mathrm{BCI}$ alone resulted in a small but significant reduction in cell viability relative to control as determined by 3-(4,5-dimethylthiazol-2yl)-5-(3-carboxymethoxyphenyl)-2-(4-sulfophenyl)-2Htetrazolium) (MTS) assay $-86.3 \%(\mathrm{p}=0.007)$ and $84.7 \%$ $(\mathrm{p}=.004)$ in OVCAR8 and SKOV3, respectively. In both cell lines, co-treatment with $\mathrm{BCI}$ and $100 \mu \mathrm{M}$ carboplatin resulted in a statistically significant synergistic effect on cytotoxicity compared to either treatment alone. Carboplatin alone treatment resulted in $88.8 \%(\mathrm{p}=0.002)$ and $86.8 \%\left(\mathrm{p}=4.9 \times 10^{-4}\right)$ survival in OVCAR8 and SKOV3 cells, respectively, while BCI with carboplatin resulted in $33.3 \%\left(\mathrm{p}=2.51 \times 10^{-7}\right)$ and $50.1 \%\left(\mathrm{p}=5.46 \times 10^{-7}\right)$ survival in OVCAR8 and SKOV3 cells, respectively. The difference between carboplatin alone and carboplatin with BCI was also statistically significant in OVCAR8 and SKOV3 $\left(\mathrm{p}=1.78 \times 10^{-7}\right.$ and $3.25 \times 10^{-6}$, respectively).

Likewise, significantly more death was noted with $\mathrm{BCI}$ and $10 \mathrm{nM}$ paclitaxel treatment, with survival of $51.4 \%$ in OVCAR8 $\left(\mathrm{p}=1.73 \times 10^{-6}\right)$ and $51.3 \%$ in SKOV3 $\left(\mathrm{p}=9.37 \times 10^{-7}\right)$ with paclitaxel alone, and $25.4 \%$ $\left(\mathrm{p}=1.8 \times 10^{-6}\right)$ and $45.0 \%\left(\mathrm{p}=9.66 \times 10^{-7}\right)$ with the addition of BCI with paclitaxel. The difference between paclitaxel alone and paclitaxel with $\mathrm{BCI}$ was statistically significant in OVCAR8 and SKOV3 $\left(\mathrm{p}=1.1 \times 10^{-4}\right.$ and 0.022 , respectively) (Figure 2A-2B). In order to verify the results at multiple doses of carboplatin, cells were treated with $3.75 \mathrm{uM}$ BCI with varying doses of carboplatin $(100,250$, $500 \mu \mathrm{M})$. At all doses tested, combinatorial treatment with $\mathrm{BCI}$ and carboplatin resulted in significantly reduced viability of OVCAR8 and SKOV3 cells compared to carboplatin alone (Figure 2C-2D).

\section{DUSP6 inhibition alters expression of ERK pathway responsive genes}

In order to determine how regulation of ERK signaling by BCI versus rHE4 might affect downstream gene expression, we treated cells with $\mathrm{BCI}$ alone or in combination with rHE4, paclitaxel, or carboplatin, and examined expression of the ERK pathway response genes EGR1 and c-JUN. EGR1 is a transcription factor involved in promoting apoptosis in many cancers [26-29], and is involved in cisplatin resistance in esophageal and ovarian cancer cells $[29,30]$. We have previously shown that HE4 suppresses cisplatin-induced EGR1 gene upregulation in SKOV3 cells [9]. On the other hand, c-JUN is a transcription factor involved in promoting cell survival and growth, and is associated with resistance to platinumbased chemotherapy [31].

Treatment with BCI modestly upregulated EGR1 expression by 1.48 -fold $(\mathrm{p}=0.022)$ and 1.63 -fold $\left(\mathrm{p}=1.2 \times 10^{-}\right.$ ${ }^{4}$ ) in OVCAR8 and SKOV3 cells, respectively. Conversely, treatment with rHE4 resulted in 0.56 -fold $(\mathrm{p}=0.0016)$ and 0.55 -fold $\left(\mathrm{p}=2.5 \times 10^{-4}\right)$ reduced EGR1 expression relative to control in OVCAR8 and SKOV3, respectively - a result that is in agreement with our previous study showing HE4 suppresses cisplatin-mediated upregulation of EGR1 [9]. The effect of BCI on EGR1 expression was more apparent with rHE4 co-treatment, where it significantly reversed the downregulation of EGR1 by rHE4 in OVCAR8 $(\mathrm{p}=0.016)$ and SKOV3 $(\mathrm{p}=0.026)$. Furthermore, co-treatment with BCI and either paclitaxel or carboplatin upregulated expression of EGR1 compared to treatment with either chemo drug alone. EGR1 levels were increased by 2.35 -fold with paclitaxel and BCI versus 1.38-fold with paclitaxel alone $(\mathrm{p}=0.005)$. Although the response was not as robust with paclitaxel, a similar trend was observed with carboplatin co-treatment (Figure 3A-3B).

Conversely, treatment with $\mathrm{BCI}$ resulted in 0.86-fold $(\mathrm{n} / \mathrm{s})$ and 0.78 -fold $(\mathrm{p}=0.004)$ reduced $\mathrm{c}-\mathrm{JUN}$ levels relative to control in OVCAR8 and SKOV3 cells, respectively, while rHE4 upregulated c-JUN by 1.32 -fold (n/s) and $1.60-$ fold (n/s). Again, co-treatment with BCI and rHE4 reversed the upregulation of c-JUN by rHE4. We also observed a decrease in c-JUN levels in BCI and chemotherapy treated groups compared to chemotherapy alone groups, although only the carboplatin versus $\mathrm{BCI} /$ carboplatin result in SKOV3 cells reached the cutoff for significance $(\mathrm{p}=0.039$; Figure 3C-3D). Collectively, these results show that BCI opposes the effects of HE4 on EGR1 and c-JUN expression, and promotes EGR1 expression while suppressing c-JUN expression in cells exposed to chemotherapeutic drugs.

\section{DUSP6 inhibition alters ovarian cancer cells' chemotherapy response genomic profile}

In order to gain a further understanding of the effect of BCI combinatorial treatment on gene expression profiles, RNA from SKOV3 cells treated with vehicle, $\mathrm{BCI}$, carboplatin, $\mathrm{BCI} /$ carboplatin, paclitaxel, and $\mathrm{BCI} /$ paclitaxel was used on a pathway-focused qPCR array for Human Cancer Drug Resistance (Qiagen, PAHS004Z). The heat map represents the similarities in profiles between carboplatin and BCI. The carboplatin/ $\mathrm{BCI}$ profile shares similarities with both the carboplatin alone or $\mathrm{BCI}$ alone profile. The paclitaxel gene profile stands out as unique, while $\mathrm{BCI} /$ paclitaxel shows a mixed expression signature between $\mathrm{BCI}$ alone and paclitaxel alone treatments (Figure 4). Collectively, the genomic 
analysis of cells treated with BCI and chemotherapy agents reveal that BCI promotes similar chemo-response and cell death pathways as carboplatin. However, a more in-depth analysis of the specific genes regulated by each of these treatments revealed differences that may contribute to the role of DUSP6 in the increased chemosensitivity of these cells.

The top five upregulated and downregulated genes from each treatment comparison are outlined in Table 1. We observed a very similar expression profile with BCI alone and carboplatin alone treatments, with the top increased mRNAs compared to control with either treatment being ELK1, GAPDH, ERBB2, ABCC1, BCL2L1, and PPARD, and the most reduced mRNAs including Cytochrome P450 family genes, as well as CDKN2A and AR. BCI/carboplatin co-treatment also produced similar effects on gene expression as carboplatin alone or BCI alone. The top genes upregulated in all three groups relative to control were ELK1, GAPDH, ERBB2, ABCC1, BCL2L1, and PPARD. Conversely, ERBB3 and RARB were the genes most downregulated with $\mathrm{BCI} /$ carboplatin co-treatment compared to control, which differed from BCI alone or carboplatin alone treatments.

Paclitaxel treatment alone produced a unique gene expression signature, with top genes upregulated compared to control being RARA, CCND1, BCL2L1, NFKB2, and NFKBIB. The most downregulated genes were RARB, ATM, ARNT, BCL2, and NAT2. BCI and paclitaxel co-treatment produced a mixed signature, with
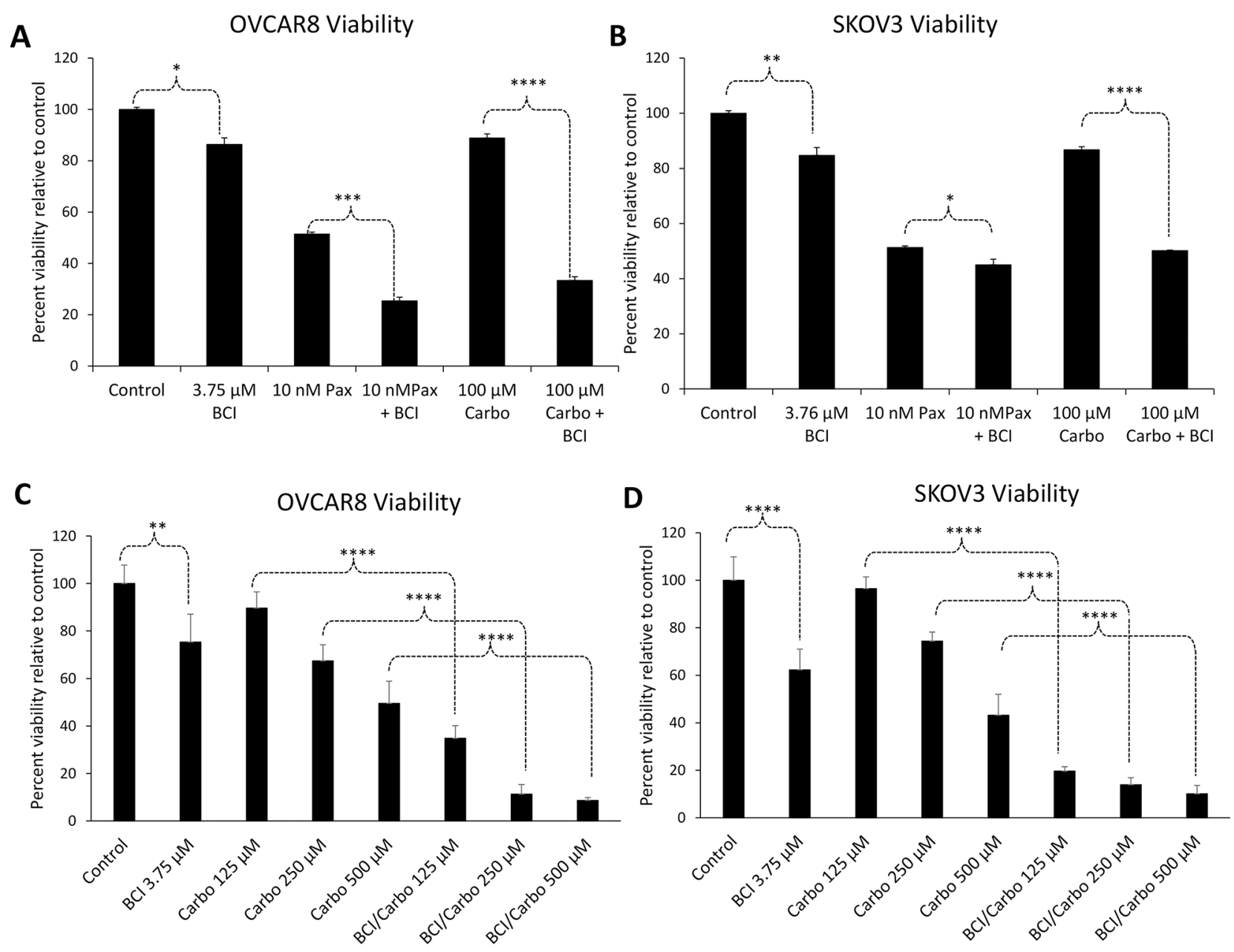

Figure 2: Inhibition of DUSP6 sensitizes ovarian cancer cells to chemotherapeutic drugs. OVCAR8 cells (A) and SKOV3 cells (B) exhibited reduced viability by MTS assay when co-treated for $24 \mathrm{~h}$ with the DUSP6 inhibitor BCI and either paclitaxel or carboplatin compared to either chemotherapeutic agent alone. OVCAR8 cells (C) and SKOV3 cells (D) were treated with various doses of carboplatin alone or in combination with $3.75 \mathrm{uM} \mathrm{BCI}$ for $24 \mathrm{~h}$. Cell viability was measured with MTS assay. A synergistic effect was observed with the addition of BCI to carboplatin at all doses tested. Error bars represent standard deviation from $\geq 3$ biological replicates. For clarity, only significance between Ctrl vs. BCI and single agent chemo vs. BCI+chemo are indicated on the graph. Error bars represent standard deviation of $\geq 3$ biological replicates. ${ }^{*} \mathrm{p}<0.05,{ }^{* *} \mathrm{p}<0.005 ;{ }^{* * *} \mathrm{p}<.0005,{ }^{* * * *} \mathrm{p}<.00005$. 
A

OVCAR8 EGR1 Gene Expression

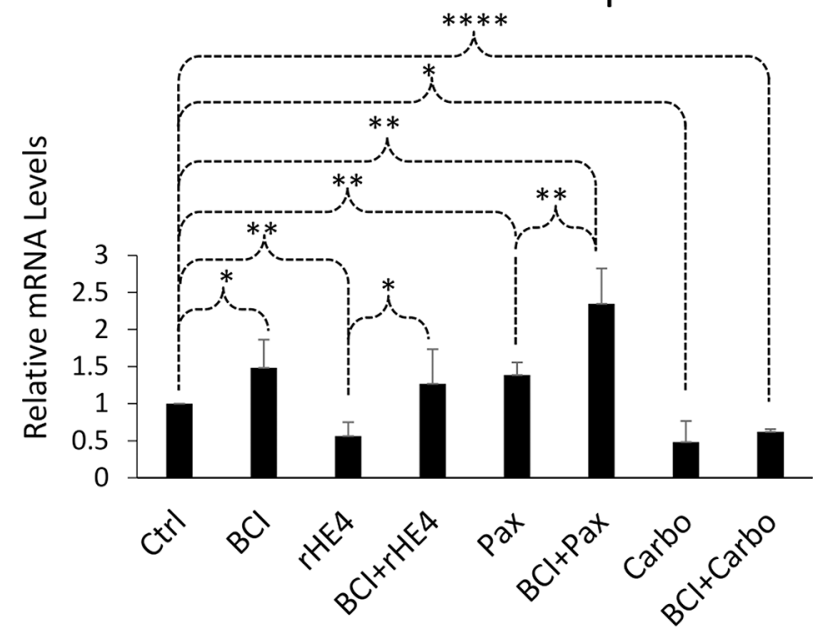

C OVCAR8 c-Jun Gene Expression

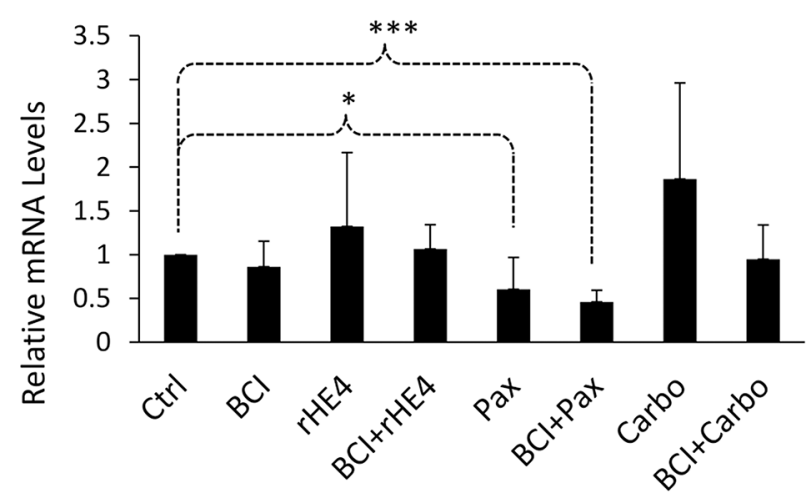

B

SKOV3 EGR1 Gene Expression

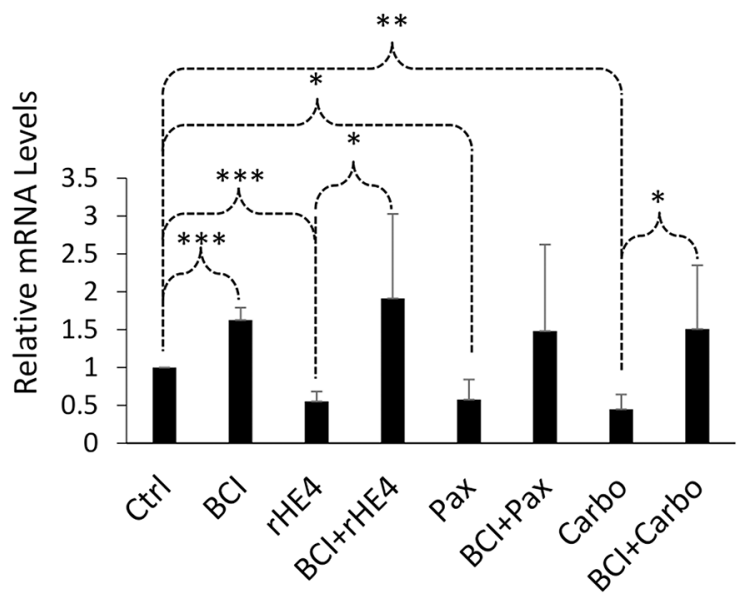

D SKOV3 c-Jun Gene Expression

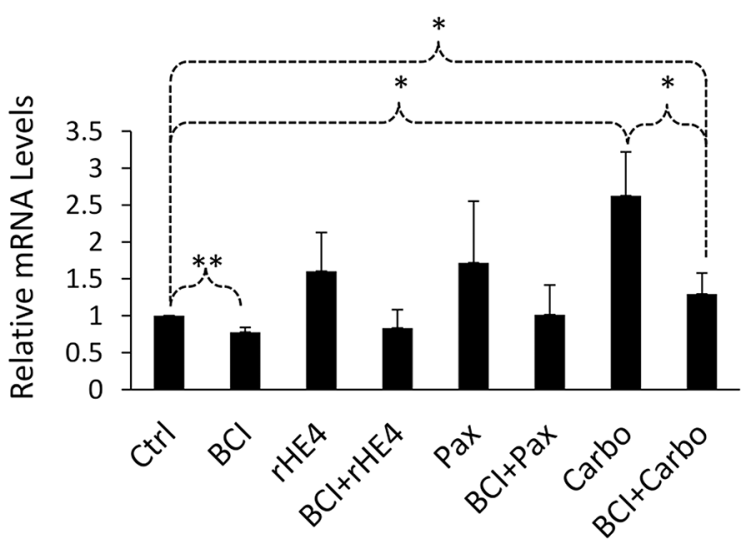

Figure 3: DUSP6 inhibition alters expression of ERK pathway responsive genes. OVCAR8 and SKOV3 cells were treated with BCI, carboplatin, BCI+carboplatin, paclitaxel, or BCI+paclitaxel for $24 \mathrm{~h}$ and qPCR was performed. (A) BCI opposed the effect of rHE4 on EGR1 levels in OVCAR8 cells, and EGR1 mRNA levels were higher in cells co-treated with BCI and chemotherapeutic drugs than in cells treated with chemotherapy alone. (B) BCI opposed the effect of rHE4 on c-JUN levels in OVCAR8 cells, and c-JUN mRNA levels were lower in cells co-treated with BCI and chemotherapeutic drugs than in cells treated with chemotherapy alone. (C) BCI opposed the effect of rHE4 on EGR1 levels in SKOV3 cells, and EGR1 mRNA levels were higher in cells co-treated with BCI and chemotherapeutic drugs than in cells treated with chemotherapy alone. (D) BCI opposed the effect of rHE4 on c-JUN levels in SKOV3 cells, and c-JUN mRNA levels were lower in cells co-treated with BCI and chemotherapeutic drugs than in cells treated with chemotherapy alone. Error bars represent standard deviation of $\mathrm{n} \geq 3$ independent experiments. ${ }^{*} \mathrm{p}<.05 ;{ }^{* *} \mathrm{p}<.005 ;{ }^{* * *} \mathrm{p}<.0005 ;{ }^{* * *} \mathrm{p}<.00005$.

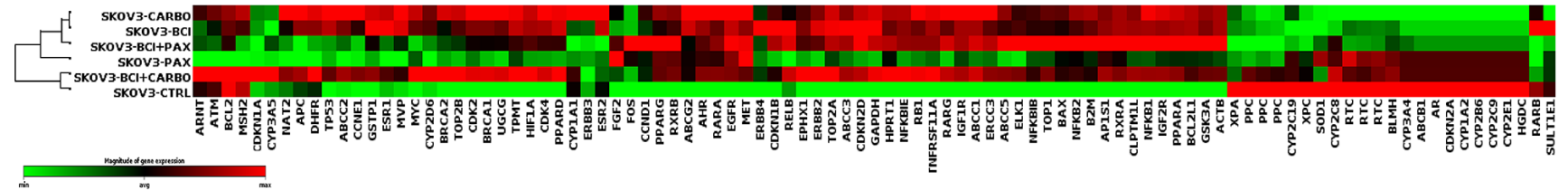

Figure 4: DUSP6 inhibition alters ovarian cancer cells' chemotherapy response genomic profile. Heatmap of gene expression (analyzed by Human Cancer Drug Resistance pathway focused qPCR array) in SKOV3 cells treated with BCI, carboplatin, paclitaxel, or chemotherapy in combination with BCI. Clustering, performed by the Qiagen GeneGlobe Data Analysis Center, indicates groups with most similarity between each other. 
Table 1: Most differentially expressed genes from pathway focused qPCR array

\begin{tabular}{|c|c|c|c|c|}
\hline Group Comparison & Gene & Fold-change (up) & Gene & Fold-change (down) \\
\hline \multirow[t]{5}{*}{ BCI vs. Ctrl } & $\overline{E L K 1}$ & 29.2 & CYP2E1 & -2.42 \\
\hline & GAPDH & 28.47 & CYP1A2 & -2.42 \\
\hline & ERBB2 & 23.48 & CDKN2A & -2.42 \\
\hline & ABCC1 & 23.02 & AR & -2.42 \\
\hline & BCL2L1 & 18.04 & $\mathrm{ABCB} 1$ & -2.42 \\
\hline \multirow[t]{5}{*}{ Carbo vs. Ctrl } & $\mathrm{ABCC} 1$ & 27.74 & CYP3A4 & -2.76 \\
\hline & ELK1 & 27.47 & CYP2B6 & -2.76 \\
\hline & GAPDH & 26.35 & CDKN2A & -2.76 \\
\hline & RARG & 20.72 & SULT1E1 & -2.76 \\
\hline & ERBB2 & 19.01 & $\mathrm{AR}$ & -2.76 \\
\hline \multirow[t]{5}{*}{ BCI/Carbo vs. Ctrl } & ELK1 & 33.41 & ERBB3 & -3.18 \\
\hline & GAPDH & 27.79 & RARB & -2.70 \\
\hline & $\mathrm{ABCC} 1$ & 25.27 & XPA & -2.08 \\
\hline & ERBB2 & 24.92 & & \\
\hline & PPARD & 19.00 & & \\
\hline \multirow[t]{5}{*}{ Pax vs. Ctrl } & RARA & 11.16 & RARB & -5.48 \\
\hline & CCND1 & 9.64 & ATM & -5.19 \\
\hline & BCL2L1 & 9.46 & ARNT & -3.53 \\
\hline & NFKB2 & 8.90 & BCL2 & -3.17 \\
\hline & NFKBIB & 8.73 & NAT2 & -2.88 \\
\hline \multirow[t]{5}{*}{ BCI/Pax vs. Ctrl } & ELK1 & 44.81 & RARB & -5.53 \\
\hline & $\mathrm{ABCC} 1$ & 25.65 & $\mathrm{XPA}$ & -3.79 \\
\hline & GAPDH & 25.28 & APC & -2.52 \\
\hline & NFKBIB & 24.27 & CYP1A1 & -2.38 \\
\hline & BCL2L1 & 21.26 & MSH2 & -2.13 \\
\hline \multirow[t]{5}{*}{ BCI/Carbo vs. Carbo } & CYP2C8 & 2.57 & ERBB3 & -15.13 \\
\hline & CYP3A5 & 2.22 & RARB & -2.05 \\
\hline & CYP2B6 & 2.15 & & \\
\hline & CYP1A2 & 2.15 & & \\
\hline & CYP3A4 & 2.15 & & \\
\hline \multirow[t]{5}{*}{ BCI/Pax vs. Pax } & ELK1 & 16.69 & ERBB3 & -2.07 \\
\hline & RELB & 9.16 & & \\
\hline & RARG & 6.59 & & \\
\hline & ERBB2 & 5.95 & & \\
\hline & GAPDH & 5.84 & & \\
\hline
\end{tabular}

ELK1, ABCC1, GAPDH, NFKBIB, and BCL2L1 being the most upregulated genes, and RARB, XPA, APC, CYP1A1, and MSH2 being the most downregulated.
Further comparisons were performed between carboplatin or paclitaxel alone and in combination with BCI. The differences in upregulated genes between $\mathrm{BCI} /$ 
carboplatin and carboplatin alone were modest and comprised Cytochrome P450 family genes. Only two genes were downregulated in $\mathrm{BCI} /$ carboplatin versus carboplatin alone, and of those, only ERBB3 showed robust downregulation. The differences in upregulated genes between paclitaxel/BCI and paclitaxel alone reflected the addition of BCI to paclitaxel. There was robust upregulation of ELK1, ERBB2, RARG, GAPDH, and RELB with cotreatment, which was not noted with paclitaxel treatment alone, as well as modest downregulation of ERBB3. A similar suppression of ERBB3 was observed in OVCAR8 cells treated with BCI and chemotherapeutic drugs (Supplementary Figure 3). The complete results of the qPCR array can be found in Supplementary Dataset 1.

\section{DUSP6 levels are upregulated in EOC tissue compared to adjacent normal tissue, and correlate with HE4 tissue levels}

To verify the clinical relevance of our findings, we performed immunohistochemistry of DUSP6 in an EOC tumor microarray and compared levels in serous adenocarcinoma samples $(n=40)$ to levels in normal adjacent tissue (NAT; $n=7$ ). Mean intensity of DUSP6 was $573(+/-19.6)$ in EOC samples, and $432(+/-24.5)$ in NAT $(p=0.0027)$. Moreover, maximal intensity was significantly greater in serous EOC samples than NAT. Maximum intensity was $1632(+/-109.6)$ for EOC and $900(+/-110.3)$ for NAT $(p=0.0045)$, indicating that some areas of EOC exhibited particularly strong staining for DUSP6 (Figure 5A). Representative images are shown in Figure 5B.

In order to determine if a correlation exists between HE4 levels and DUSP6 levels in EOC, we costained for both proteins in the ovarian tissue microarray, and calculated correlations for mean intensity values and integrated optical density (IOD). Spearman Rank correlation test revealed a positive correlation between DUSP6 and HE4 mean intensities $(\mathrm{R}=0.45, \mathrm{p}=0.0038)$ and IOD values $\left(\mathrm{R}=0.64, \mathrm{p}=1.0 \times 10^{-5}\right)$ (Figure $\left.5 \mathrm{C}-5 \mathrm{D}\right)$. Together, these results suggest that DUSP6 may be involved in promoting tumorigenesis and chemoresistance in EOC, and highlight a relationship between HE4 and DUSP6 in vitro and in EOC.

\section{DISCUSSION}

In this study, we found that HE4 promotes upregulation of DUSP6 in ovarian cancer cells, and that levels of these proteins positively correlate in EOC tissue. We also determined that inhibition of DUSP6 promotes chemosensitivity of two different ovarian cancer cell lines, which coincided with increased expression of pro-apoptotic EGR1, and reduced expression of oncogenic c-JUN. Lastly, we examined the genomic signature of cells treated with a DUSP6 inhibitor alone or in combination with the chemotherapeutic drugs carboplatin or paclitaxel, and found a reduction in ERBB3 mRNA with $\mathrm{BCI}$ and chemotherapy co-treatment compared to chemotherapy alone.

The nature of the relationship between HE4 and DUSP6 was revealed by examining the effect of DUSP6 inhibition and ERK inhibition on HE4 and DUSP6 levels. Counter to our expectations, inhibition of DUSP6 with BCI actually resulted in an upregulation of HE4. This may be explained by BCI-mediated upregulation of phospho-ERK leading to an upregulation of HE4, since our previous published data showed that activation of the epidermal growth factor receptor (EGFR) signaling pathway leads to an increase in HE4 [14]. However, it does highlight the fact that activation of phospho-ERK via different mechanisms may produce differing effects on both gene expression and cell behavior. Moreover, while ERK inhibition produced an expected suppression of DUSP6 levels, it actually increased HE4 levels, again highlighting an as yet unexplained relationship between DUSP6, HE4, and ERK signaling. There are likely many time- and context-dependent pathways and feedback mechanisms that play a role in the regulation of HE4 and DUSP6.

The two ERK responsive genes we characterized show opposite expression patterns with BCI treatment. EGR1 is activated by ERK via the transcription factor ELK-1, and EGR1 is itself a transcription factor that activates expression of genes regulating proliferation, differentiation, and apoptosis $[32,33]$. A previous study by our lab showed that HE4 overexpression in SKOV3 cells suppresses cisplatin-mediated upregulation of EGR1 [9]. In the present study, we observed that HE4 downregulated EGR1 expression, which is consistent with these previous results. Conversely, BCI treatment opposed the effect of rHE4 on EGR1 expression. c-JUN, which is also an ERK responsive gene, was regulated in the opposite direction as EGR1. rHE4 treatment upregulated expression of c-JUN, which is consistent with its role as a promoter of tumor growth and proliferation $[6,7,13,14,16]$. Meanwhile, BCI again opposed this effect in BCI and rHE4 co-treated cells. Furthermore, BCI suppressed chemotherapy-mediated increases in c-JUN levels. The effects of BCI on EGR1 and c-JUN together may contribute to the overall increased efficacy of BCI and chemotherapy treatment over chemotherapy alone, and could explain the opposing effects of BCI and HE4 on chemotherapy response.

The pathway focused qPCR array revealed further differences in gene expression profiles between the different treatment groups. As expected, ELK1, an ERK response gene that encodes for a transcription factor that regulates ERK response genes such as EGR1, was upregulated with $\mathrm{BCI}$ treatment, as well as carboplatin alone. Co-treatment with BCI and carboplatin resulted in similar expression profiles as either treatment alone, save for a robust decrease in ERBB3 gene expression with co-treatment compared to 
carboplatin treatment alone, suggesting that downregulation of ERBB3 may also be involved in the increased efficacy of co-treatment. ERBB3 (HER3) is a type 1 receptor tyrosine kinase (RTK) that lacks intrinsic kinase function, and must dimerize with another ERBB receptor - particularly ERBB2 (HER2) - to activate signaling. ERBB3 is as a potent partner for and may even be required to maintain the oncogenic activity of ERBB2, which has no known ligand [34-41]. Upon ERBB3 ligand binding and subsequent hetero-dimerization with ERBB2, diverse signaling pathways may be activated, such as the PI3K/AKT pathway, which is heavily involved in promoting chemoresistance in many cancers [42-44]. Most importantly, a role for ERBB3 has been described in promoting chemoresistance and tumor progression in ovarian cancer [45-47].

In contrast to the effects of carboplatin or BCI on SKOV3 cells, paclitaxel elicited a markedly different expression profile. Combinatorial treatment with $\mathrm{BCI}$ and paclitaxel produced increases in BCI regulated genes such as ELK1 and ERBB2 compared to paclitaxel alone, and also elicited a small reduction in ERBB3 levels as well. Therefore, it is possible that the increase in cell
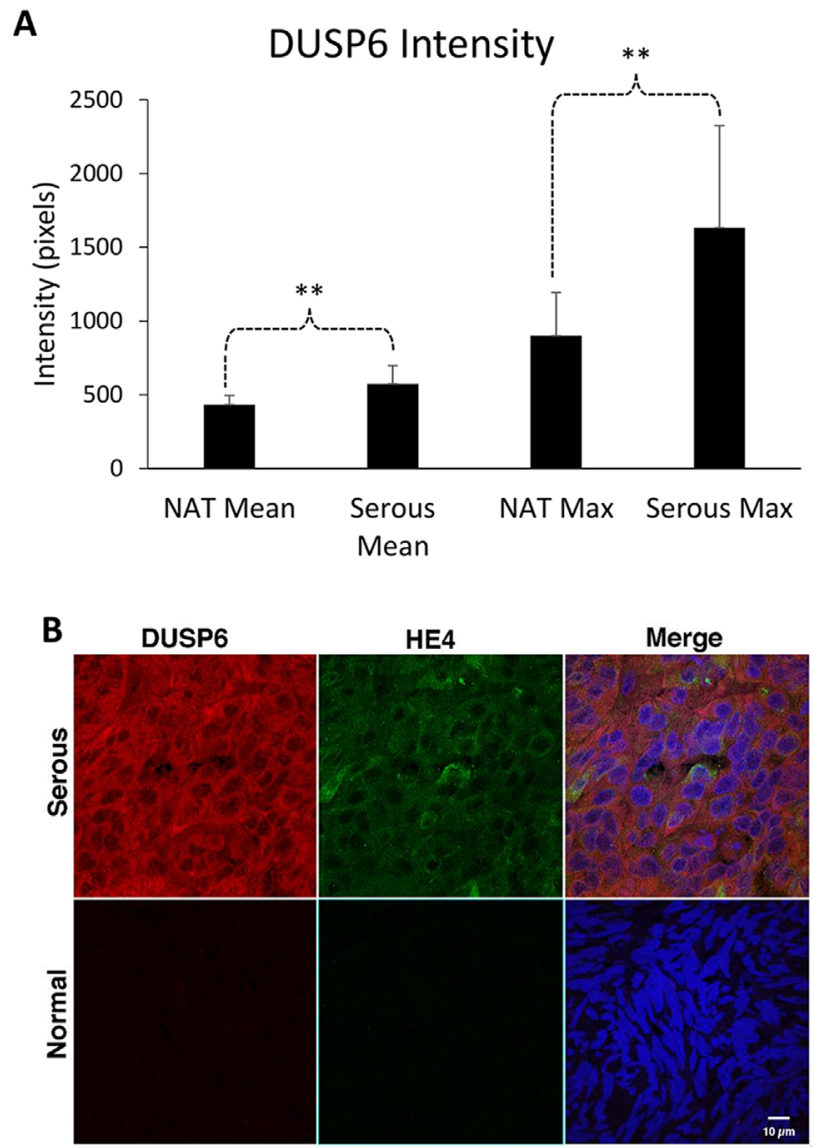

death elicited by co-treatment with paclitaxel and BCI may occur via the upregulation of certain BCI-regulated genes, as well as the downregulation of ERBB3. Further studies are required to elucidate the exact involvement of ERBB3, ELK1 and its downstream effectors such as EGR1, as well as c-JUN, on the synergistic effect of BCI on cytotoxicity. It is important to mention that BCI also possesses activity against another DUSP-family member, DUSP1 [48]. DUSP1 is a class -1 DUSP that has selectivity for JNK, ERK, and p38. DUSP1 possesses the strongest selectivity for JNK, unlike DUSP6, which only possesses substrate selectivity for ERK [49]. Therefore, we cannot discount that the activity of BCI on DUSP1 could also be influencing phospho-ERK signaling and chemoresponse. However, since we are primarily interested in the clinical relevance of a small molecule inhibitor, we chose to use BCI in our study despite this potential off target effect.

The specific role of DUSP6 in the context EOC is not well established. One report showed that DUSP6 appears to function as a tumor suppressor in EOC [25], but our results suggest the opposite effect. Therefore, further study is needed to fully elucidate the role of DUSP6 and

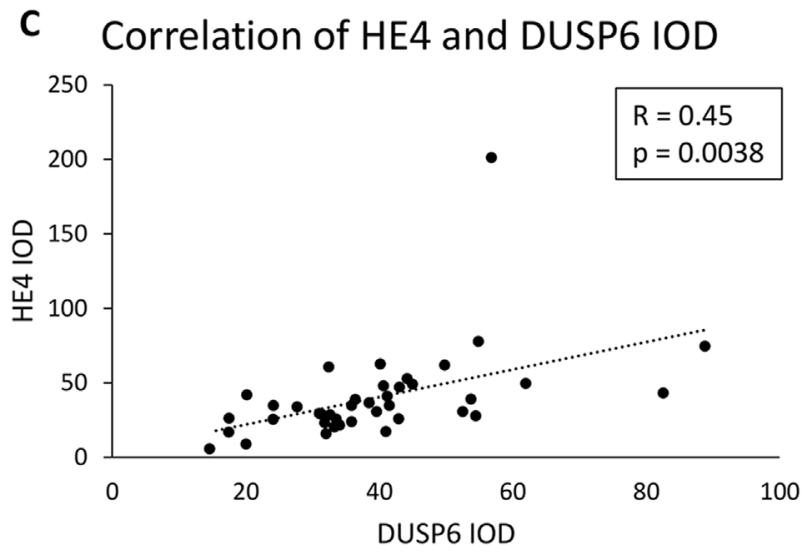

D

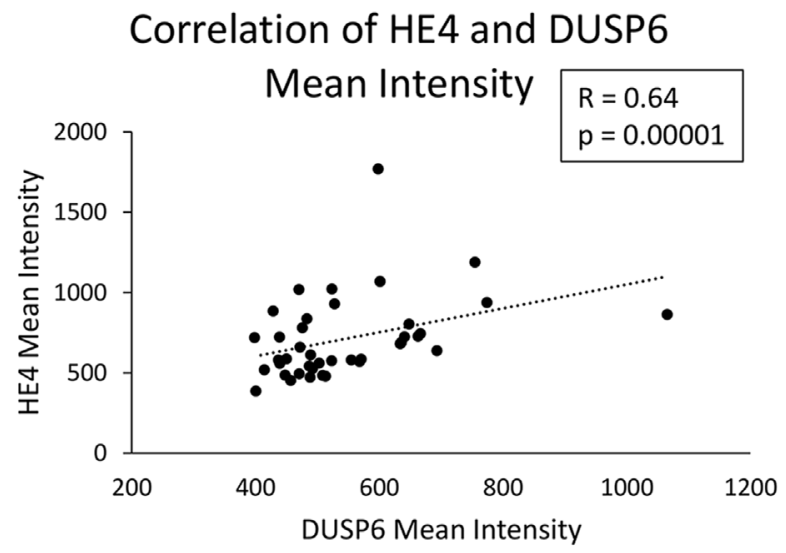

Figure 5: DUSP6 levels are higher in EOC tissue than normal adjacent tissue, and correlate with HE4 tissue levels (A). DUSP6 mean and maximum intensity staining is higher in serous EOC tissue $(n=40)$ than in normal adjacent tissue (NAT) ( $n=7)$. Error bars represent standard deviation. ${ }^{* *} \mathrm{p}<0.005$ (B) Representative images of NAT and serous EOC DUSP6 staining. (C) Correlation of DUSP6 and HE4 mean intensity. (D) Correlation of DUSP6 and HE4 integrated optical density (IOD). 
determine if its function is context dependent. In general, DUSP6 remains an interesting protein in that it has opposing roles in different tumor types. In some cancers, it appears to act as a tumor suppressor, while in others it acts to promote tumorigenesis and aggressive behavior [20-25]. Our results are consistent with a recent study by $\mathrm{Wu}$ et al. (2018) showing DUSP6 involvement in cisplatin resistance in gastric cancer [23]. The authors observed an increase in phospho-ERK with BCI treatment, but a downregulation of the ERK-response genes RPS6KA1, EGR1, MMP2, MMP9, MYC, and ELK3, again showing that activation of ERK does not automatically lead to activation of its target genes. In our study, we observed different effects of DUSP6 inhibition on ERK-response genes depending upon gene function-namely, upregulation of EGR1 and downregulation of c-JUN. Furthermore, Wu et al. found that BCI treatment enhanced cisplatin sensitivity in gastric cancer cells and in vivo xenografts. Collectively, our study and the one by $\mathrm{Wu}$ et al. illustrate that the relationship between ERK activation and downstream gene activation is not straightforward, and appears to be highly contextdependent. Therefore, although BCI serves to increase ERK activation and increase HE4 levels, it has differing effects on ERK response genes, which can potentially be manipulated to enhance chemotherapy efficacy.

In conclusion, this study highlights a novel function of DUSP6 in EOC, and reveals that it may be involved in regulating chemoresponse. Targeting HE4 and/or DUSP6 in EOC may be an effective method of reversing chemoresistance and improving long-term response rates in selected patient populations.

\section{MATERIALS AND METHODS}

\section{Cell culture and treatments}

SKOV3 and OVCAR8 cells were obtained from American Type Culture Collection (ATCC) and kept at low passage in Dulbecco Modified Eagle Medium (DMEM) with 10\% fetal bovine serum and 1\% penicillin/ streptomycin, in a humidified incubator at $37^{\circ} \mathrm{C} / 5 \%$ $\mathrm{CO}_{2}$. Cells were plated at sub-confluent density the day before treatments. Cells were treated with $3.75 \mu \mathrm{M}$ BCI (Sigma Aldrich, B4313), $20 \mathrm{nM}$ recombinant HE4 (My BioSource, MBS355616 or Raybiotech, 230-30001-10), $100 \mu \mathrm{M}$ carboplatin (Sigma Aldrich, C2538), $10 \mathrm{nM}$ paclitaxel (Sigma Aldrich, T7402), or control treatments $\left(0.037 \% \mathrm{DMSO}\right.$ and/or $\left.\mathrm{H}_{2} 0\right)$ for indicated time points. SKOV3-NV, SKOV3-C1, and SKOV3-C1-CRISPR cell lines were generated as previously described $[9,14]$.

\section{Western Blot}

Western blot was performed as previously described [10]. GAPDH was used as a loading control. Antibodies and dilutions used are as follows:
MKP-3 (DUSP6) (Santa Cruz, sc-377070; 1:100 or

Novus Biologicals, NBP2-67320, 1:50)

HE4 (Origene, TA307787, 1:2000)

GAPDH (Cell Signaling, 2118, 1:2000)

Phospho-p44/42 (ERK1/2) (Cell Signaling, 9101, $1: 2000)$

\section{Densitometry}

Image $\mathrm{J}$ "analyze gel" function was used to perform densitometry analysis of western blot images in 8-bit TIFF format. Band densities were normalized to GAPDH, and the control was set to 1 for plotted graphs.

\section{Quantitative RT-PCR}

Quantitative RT-PCR was performed as previously described [10]. Validated primers for DUSP6, EGR1, c-JUN, and ERBB3 were purchased from https:// www.realtimeprimers.com. Custom primer sequences (Invitrogen) are as follows:

18s rRNA (F) - CCG CGG TTC TAT TTT GTT GG 18s rRNA (R) - GGC GCT CCC TCT TAA TCA TG

HE4 (F) - CTG CCC CCA GGT GAA CAT TA

HE4 (R) - CCA TTG CGG CAG CAT TTC AT

\section{qPCR Array}

One set of SKOV3 cell RNA from the experiment in Figure 3 was used for the qPCR array (control, $\mathrm{BCI}$, carboplatin, $\mathrm{BCI}+$ carboplatin, paclitaxel, and $\mathrm{BCI}+$ paclitaxel). RNA was reverse transcribed using the RT2 First Strand Kit (Qiagen, 330401), and cDNA was then added with SYBR green mastermix (Qiagen, 330504) to 96-well RT2 Profiler Human Cancer Drug Resistance PCR Array plates (Qiagen, PAHS-004Z), according to the manufacturer's instructions. The plates were run on an ABI 7500 qPCR machine, with $10 \mathrm{~min}$ at $95^{\circ} \mathrm{C}$, and 40 cycles of $15 \mathrm{~s}$ at $95^{\circ} \mathrm{C}$ and $1 \mathrm{~min}$ at $60^{\circ} \mathrm{C}$. An automated baseline was used, with thresholds manually adjusted to remain constant across all plates. Data was analyzed using the GeneGlobe Data Analysis Center at https://www. qiagen.com. The housekeeping gene RPLP0 was used for normalization, which was automatically selected by the software based on stable expression between treatments. Calculations of relative expression levels were performed using the using the $\Delta \Delta \mathrm{Ct}$ method All samples passed quality control standards (array reproducibility, RT efficiency, and genomic DNA contamination).

\section{Cell viability assay}

Cells were seeded at 2000 cells/well in 96-well plates, and treated as described above. After $24 \mathrm{~h}$, cell viability assays were performed by adding $10 \mu \mathrm{l} /$ well of CellTiter $96{ }^{\circledR}$ Aqueous One Solution Cell Proliferation 
MTS Assay (Promega, G3580), incubating at $37^{\circ} \mathrm{C} / 5 \%$ $\mathrm{CO}^{2}$ for $2 \mathrm{~h}$, and reading absorbance at $492 \mathrm{~nm}$. Results are displayed as percent survival relative to vehicle treated cells.

\section{Immunohistochemistry}

Immunohistochemical staining of an ovarian cancer microarray (US Biomax, OV802a) was performed as previously described [50], using antibodies for HE4 (Santa Cruz, sc-293473) and DUSP6 (MyBioSource, MBS8516662). Confocal microscopy was performed by an independent imaging technician at the Rhode Island Hospital Digital Imaging Core Facility with a Nikon C1si confocal (Nikon Inc. Mellville, NY, USA). Two to three fields/sample were randomly selected based on DAPI staining, and minimum, mean, and maximum gray values (pixels) were determined for each field. For the tumor microarray, normal adjacent tissues were used to set the threshold for positive staining. Integrated optical density (IOD) was calculated in serous samples using the mean values multiplied by the total area.

\section{Statistics}

Where statistics are shown, $n \geq 3$ biological replicates. p-values from quantitative PCR, MTS assay, and western blots were determined by unpaired, 1-tailed Student t-test. For correlation analysis, Spearman rank test was used to determine $\mathrm{R}$ value and corresponding $\mathrm{p}$-values using the calculators at https://www.socscistatistics.com. Differences were considered statistically significant when $\mathrm{p}<0.05$.

\section{Abbreviations}

DUSP6: dual specificity phosphatase 6; ERK: extracellular signal regulated kinase; HE4: human epididymis protein 4; rHE4: recombinant HE4; EOC: epithelial ovarian cancer; CA 125: cancer antigen 125; BCI: (E)-2-Benzylidene-3-(cyclohexylamino)-2,3-dihydro1H-inden-1-one; EGR1: early growth response 1; IOD: integrated optical density; NAT: normal adjacent tissue; DMEM: dulbecco's modified eagle medium; DMSO: dimethyl sulfoxide; MTS: [3-(4,5-dimethylthiazol-2yl)-5-(3-carboxymethoxyphenyl)-2-(4-sulfophenyl)-2Htetrazolium.

\section{Author contributions}

NEJ, JRR, NY, PAD, RNF, and COO contributed conceptually to this manuscript. NEJ and JRR devised experiments. NEJ, LB, MTO, AB, JBE, and JRR executed all experiments. JRR and NEJ wrote this manuscript for review and approval by all authors.

\section{ACKNOWLEDGMENTS}

We would like to sincerely thank and acknowledge the Freiman Lab (Molecular and Cellular Biology and Biochemistry Department, Brown University) for providing lab space and support during the time this research was being conducted. We would also like to thank the Brown Genomics Core Facility and the Kilguss Core Facility for use of equipment needed to conduct this study, and the Rhode Island Hospital Digital Imaging Core Facility for imaging and quantification.

\section{CONFLICTS OF INTEREST}

The authors declare no commercial or financial conflicts of interest.

\section{FUNDING}

Research reported in this publication was supported by the Division of Gynecologic Oncology, Program in Women's Oncology at Women \& Infants Hospital and Swim Across America, and the Kilguss Research Core of Women \& Infants Hospital. The Kilguss Research Core is supported by an Institutional Development Award (IDeA) from the National Institute of General Medical Sciences of the National Institutes of Health under grant number P30GM114750.

\section{REFERENCES}

1. van Zyl B, Tang D, Bowden NA. Biomarkers of platinum resistance in ovarian cancer: what can we use to improve treatment. Endocr Relat Cancer. 2018; 25:R303-18. https://doi.org/10.1530/ERC-17-0336. [PubMed]

2. Morgan RD, Clamp AR, Evans DG, Edmondson RJ, Jayson GC. PARP inhibitors in platinum-sensitive high-grade serous ovarian cancer. Cancer Chemother Pharmacol. 2018; 81:647-58. https://doi.org/10.1007/s00280-018-3532-9. [PubMed]

3. Foley OW, Rauh-Hain JA, del Carmen MG. Recurrent epithelial ovarian cancer: an update on treatment. Oncology (Williston Park). 2013; 27:288-94, 298. [PubMed]

4. Kim A, Ueda Y, Naka T, Enomoto T. Therapeutic strategies in epithelial ovarian cancer. J Exp Clin Cancer Res. 2012; 31:14. https://doi.org/10.1186/1756-9966-31-14. [PubMed]

5. Moore RG, McMeekin DS, Brown AK, DiSilvestro P, Miller MC, Allard WJ, Gajewski W, Kurman R, Bast RC Jr, Skates SJ. A novel multiple marker bioassay utilizing HE4 and CA125 for the prediction of ovarian cancer in patients with a pelvic mass. Gynecol Oncol. 2009; 112:40-46. https://doi.org/10.1016/j.ygyno.2008.08.031. [PubMed]

6. Zhu L, Zhuang H, Wang H, Tan M, Schwab CL, Deng L, Gao J, Hao Y, Li X, Gao S, Liu J, Lin B. Overexpression of 
HE4 (human epididymis protein 4) enhances proliferation, invasion and metastasis of ovarian cancer. Oncotarget. 2016; 7:729-44. https://doi.org/10.18632/oncotarget.6327. [PubMed]

7. Lu R, Sun X, Xiao R, Zhou L, Gao X, Guo L. Human epididymis protein 4 (HE4) plays a key role in ovarian cancer cell adhesion and motility. Biochem Biophys Res Commun. 2012; 419:274-80. https://doi.org/10.1016/j.bbrc.2012.02.008. [ubMed]

8. Lokich E, Singh RK, Han A, Romano N, Yano N, Kim K, Moore RG. HE4 expression is associated with hormonal elements and mediated by importindependent nuclear translocation. Sci Rep. 2014; 4:5500. https://doi.org/10.1038/srep05500. [PubMed]

9. Ribeiro JR, Schorl C, Yano N, Romano N, Kim KK, Singh RK, Moore RG. HE4 promotes collateral resistance to cisplatin and paclitaxel in ovarian cancer cells. J Ovarian Res. 2016; 9:28. https://doi.org/10.1186/s13048-016-0240-0. [PubMed]

10. Ribeiro JR, Gaudet HM, Khan M, Schorl C, James NE, Oliver MT, DiSilvestro PA, Moore RG, Yano N. Human Epididymis Protein 4 Promotes Events Associated with Metastatic Ovarian Cancer via Regulation of the Extracelluar Matrix. Front Oncol. 2018; 7:332. https://doi.org/10.3389/fonc.2017.00332. [PubMed]

11. Zhuang H, Tan M, Liu J, Hu Z, Liu D, Gao J, Zhu L, Lin B. Human epididymis protein 4 in association with Annexin II promotes invasion and metastasis of ovarian cancer cells. Mol Cancer. 2014; 13:243. https://doi.org/10.1186/1476-4598-13-243. [PubMed]

12. Zhuang H, Gao J, Hu Z, Liu J, Liu D, Lin B. Co-expression of Lewis y antigen with human epididymis protein 4 in ovarian epithelial carcinoma. PLoS One. 2013; 8:e68994. https://doi.org/10.1371/journal.pone.0068994. [PubMed]

13. Wang H, Zhu L, Gao J, Hu Z, Lin B. Promotive role of recombinant HE4 protein in proliferation and carboplatin resistance in ovarian cancer cells. Oncol Rep. 2015; 33:403-12. https://doi.org/10.3892/or.2014.3549. [PubMed]

14. Moore RG, Hill EK, Horan T, Yano N, Kim K, MacLaughlan S, Lambert-Messerlian G, Tseng YD, Padbury JF, Miller MC, Lange TS, Singh RK. HE4 (WFDC2) gene overexpression promotes ovarian tumor growth. Sci Rep. 2014; 4:3574. https://doi.org/10.1038/srep03574. [PubMed]

15. Lee S, Choi S, Lee Y, Chung D, Hong S, Park N. Role of human epididymis protein 4 in chemoresistance and prognosis of epithelial ovarian cancer. J Obstet Gynaecol Res. 2017; 43:220-27. https://doi.org/10.1111/jog.13181. [PubMed]

16. Zhu YF, Gao GL, Tang SB, Zhang ZD, Huang QS. Effect of WFDC 2 silencing on the proliferation, motility and invasion of human serous ovarian cancer cells in vitro. Asian Pac J Trop Med. 2013; 6:265-72. https://doi.org/10.1016/S1995-7645(13)60055-3. [PubMed]

17. Zhu L, Guo Q, Jin S, Feng H, Zhuang H, Liu C, Tan M, Liu J, Li X, Lin B. Analysis of the gene expression profile in response to human epididymis protein 4 in epithelial ovarian cancer cells. Oncol Rep. 2016; 36:1592-604. https://doi.org/10.3892/or.2016.4926. [PubMed]

18. Bermudez O, Pagès G, Gimond C. The dual-specificity MAP kinase phosphatases: critical roles in development and cancer. Am J Physiol Cell Physiol. 2010; 299:C189-202. https://doi.org/10.1152/ajpcell.00347.2009. [PubMed]

19. Furukawa T, Fujisaki R, Yoshida Y, Kanai N, Sunamura M, Abe T, Takeda K, Matsuno S, Horii A. Distinct progression pathways involving the dysfunction of DUSP6/MKP-3 in pancreatic intraepithelial neoplasia and intraductal papillary-mucinous neoplasms of the pancreas. Mod Pathol. 2005; 18:1034-42. https://doi.org/10.1038/modpathol.3800383. [PubMed]

20. Okudela K, Yazawa T, Woo T, Sakaeda M, Ishii J, Mitsui H, Shimoyamada H, Sato H, Tajiri M, Ogawa N, Masuda M, Takahashi T, Sugimura H, Kitamura H. Down-regulation of DUSP6 expression in lung cancer: its mechanism and potential role in carcinogenesis. Am J Pathol. 2009; 175:86781. https://doi.org/10.2353/ajpath.2009.080489. [PubMed]

21. Messina S, Frati L, Leonetti C, Zuchegna C, Di Zazzo E, Calogero A, Porcellini A. Dual-specificity phosphatase DUSP6 has tumor-promoting properties in human glioblastomas. Oncogene. 2011; 30:3813-20. https://doi.org/10.1038/onc.2011.99. [PubMed]

22. Lucci MA, Orlandi R, Triulzi T, Tagliabue E, Balsari A, Villa-Moruzzi E. Expression profile of tyrosine phosphatases in HER2 breast cancer cells and tumors. Cell Oncol. 2010; 32:361-72. https://doi.org/10.3233/CLO-2010-0520. [PubMed]

23. Wu QN, Liao YF, Lu YX, Wang Y, Lu JH, Zeng ZL, Huang QT, Sheng H, Yun JP, Xie D, Ju HQ, Xu RH. Pharmacological inhibition of DUSP6 suppresses gastric cancer growth and metastasis and overcomes cisplatin resistance. Cancer Lett. 2018; 412:243-55. https://doi.org/10.1016/j.canlet.2017.10.007. [PubMed]

24. Shojaee S, Caeser R, Buchner M, Park E, Swaminathan S, Hurtz C, Geng H, Chan LN, Klemm L, Hofmann WK, Qiu YH, Zhang N, Coombes KR, et al. Erk Negative Feedback Control Enables Pre-B Cell Transformation and Represents a Therapeutic Target in Acute Lymphoblastic Leukemia. Cancer Cell. 2015; 28:114-28. https://doi.org/10.1016/j.ccell.2015.05.008. [PubMed]

25. Chan DW, Liu VW, Tsao GS, Yao KM, Furukawa T, Chan KK, Ngan HY. Loss of MKP3 mediated by oxidative stress enhances tumorigenicity and chemoresistance of ovarian cancer cells. Carcinogenesis. 2008; 29:1742-50. https://doi.org/10.1093/carcin/bgn167. [PubMed]

26. Boone DN, Qi Y, Li Z, Hann SR. Egr1 mediates p53-independent c-Myc-induced apoptosis via a noncanonical ARF-dependent transcriptional mechanism. Proc Natl Acad Sci U S A. 2011; 108:632-37. https://doi.org/10.1073/pnas.1008848108. [PubMed]

27. Yoon TM, Kim SA, Lee DH, Lee JK, Park YL, Lee $\mathrm{KH}$, Chung IJ, Joo YE, Lim SC. EGR1 regulates radiation-induced apoptosis in head and neck squamous 
cell carcinoma. Oncol Rep. 2015; 33:1717-22. https://doi.org/10.3892/or.2015.3747. [PubMed]

28. Mohamad T, Kazim N, Adhikari A, Davie JK. EGR1 interacts with TBX2 and functions as a tumor suppressor in rhabdomyosarcoma. Oncotarget. 2018; 9:18084-98. https://doi.org/10.18632/oncotarget.24726. [PubMed]

29. He J, Yu JJ, Xu Q, Wang L, Zheng JZ, Liu LZ, Jiang BH. Downregulation of ATG14 by EGR1-MIR152 sensitizes ovarian cancer cells to cisplatin-induced apoptosis by inhibiting cyto-protective autophagy. Autophagy. 2015; 11:373-84. https://doi.org/10.1080/15548627.2015.1009781. [PubMed]

30. Dong Q, Zhang J, Hendricks DT, Zhao X. GRO $\beta$ and its downstream effector EGR1 regulate cisplatin-induced apoptosis in WHCO1 cells. Oncol Rep. 2011; 25:1031-37. https://doi.org/10.3892/or.2011.1163. [PubMed]

31. Yan D, An G, Kuo MT. C-Jun N-terminal kinase signalling pathway in response to cisplatin. J Cell Mol Med. 2016; 20:2013-19. https://doi.org/10.1111/jcmm.12908. [PubMed]

32. Manente AG, Pinton G, Tavian D, Lopez-Rodas G, Brunelli E, Moro L. Coordinated sumoylation and ubiquitination modulate EGF induced EGR1 expression and stability. PLoS One. 2011; 6:e25676. https://doi.org/10.1371/journal.pone.0025676. [PubMed]

33. Baron V, Adamson ED, Calogero A, Ragona G, Mercola D. The transcription factor Egr1 is a direct regulator of multiple tumor suppressors including TGFbeta1, PTEN, p53, and fibronectin. Cancer Gene Ther. 2006; 13:115-24. https://doi.org/10.1038/sj.cgt.7700896. [PubMed]

34. Lee-Hoeflich ST, Crocker L, Yao E, Pham T, Munroe X, Hoeflich KP, Sliwkowski MX, Stern HM. A central role for HER3 in HER2-amplified breast cancer: implications for targeted therapy. Cancer Res. 2008; 68:5878-87. https://doi.org/10.1158/0008-5472.CAN-08-0380. [PubMed]

35. Alimandi M, Romano A, Curia MC, Muraro R, Fedi P, Aaronson SA, Di Fiore PP, Kraus MH. Cooperative signaling of ErbB3 and ErbB2 in neoplastic transformation and human mammary carcinomas. Oncogene. 1995; 10:1813-21. [PubMed]

36. Hsieh AC, Moasser MM. Targeting HER proteins in cancer therapy and the role of the non-target HER3. Br J Cancer. 2007; 97:453-57. https://doi.org/10.1038/sj.bjc.6603910. [PubMed]

37. Chakrabarty A, Rexer BN, Wang SE, Cook RS, Engelman JA, Arteaga CL. H1047R phosphatidylinositol 3-kinase mutant enhances HER2-mediated transformation by heregulin production and activation of HER3. Oncogene. 2010; 29:5193-203. https://doi.org/10.1038/onc.2010.257. [PubMed]

38. Liu B, Ordonez-Ercan D, Fan Z, Edgerton SM, Yang $X$, Thor AD. Downregulation of erbB3 abrogates erbB2-mediated tamoxifen resistance in breast cancer cells. Int $\mathrm{J}$ Cancer. 2007; 120:1874-82. https://doi.org/10.1002/ijc.22423. [PubMed]

39. Berger MB, Mendrola JM, Lemmon MA. ErbB3/ HER3 does not homodimerize upon neuregulin binding at the cell surface. FEBS Lett. 2004; 569:332-36. https://doi.org/10.1016/i.febslet.2004.06.014. [PubMed]
40. Ma J, Lyu H, Huang J, Liu B. Targeting of erbB3 receptor to overcome resistance in cancer treatment. Mol Cancer. 2014; 13:105. https://doi.org/10.1186/1476-4598-13-105. [PubMed]

41. Wallasch C, Weiss FU, Niederfellner G, Jallal B, Issing W, Ullrich A. Heregulin-dependent regulation of HER2/neu oncogenic signaling by heterodimerization with HER3. EMBO J. 1995; 14:4267-75. https://doi.org/10.1002/j.1460-2075.1995.tb00101.x. [PubMed]

42. Citri A, Skaria KB, Yarden Y. The deaf and the dumb: The biology of ErbB-2 and ErbB-3. The EGF Receptor Family: Biologic Mechanisms and Role in Cancer. 2003; 57-68. https://doi.org/10.1016/B978-012160281-9/50005-0.

43. Suenaga A, Takada N, Hatakeyama M, Ichikawa $M$, Yu X, Tomii K, Okimoto N, Futatsugi N, Narumi T, Shirouzu M, Yokoyama S, Konagaya A, Taiji M. Novel mechanism of interaction of p85 subunit of phosphatidylinositol 3-kinase and ErbB3 receptor-derived phosphotyrosyl peptides. J Biol Chem. 2005; 280:1321-26. https://doi.org/10.1074/jbc.M410436200. [PubMed]

44. Mattoon DR, Lamothe B, Lax I, Schlessinger J. The docking protein Gab1 is the primary mediator of EGF-stimulated activation of the PI-3K/Akt cell survival pathway. BMC Biol. 2004; 2:24. https://doi.org/10.1186/1741-7007-2-24. [PubMed]

45. Mills GB, Yarden Y. The rebirth of a phoenix: ovarian cancers are addicted to ErbB-3. Cancer Cell. 2010; 17:21718. https://doi.org/10.1016/j.ccr.2010.02.023. [PubMed]

46. Sheng Q, Liu X, Fleming E, Yuan K, Piao H, Chen J, Moustafa Z, Thomas RK, Greulich H, Schinzel A, Zaghlul S, Batt D, Ettenberg S, et al. An activated ErbB3/ NRG1 autocrine loop supports in vivo proliferation in ovarian cancer cells. Cancer Cell. 2010; 17:298-310. https://doi.org/10.1016/j.ccr.2009.12.047. [PubMed]

47. Bezler M, Hengstler JG, Ullrich A. Inhibition of doxorubicininduced HER3-PI3K-AKT signalling enhances apoptosis of ovarian cancer cells. Mol Oncol. 2012; 6:516-29. https://doi.org/10.1016/j.molonc.2012.07.001. [PubMed]

48. Korotchenko VN, Saydmohammed M, Vollmer LL, Bakan A, Sheetz K, Debiec KT, Greene KA, Agliori CS, Bahar I, Day BW, Vogt A, Tsang M. In vivo structure-activity relationship studies support allosteric targeting of a dual specificity phosphatase. Chembiochem. 2014; 15:1436-45. https://doi.org/10.1002/cbic.201402000. [PubMed]

49. Ahmad MK, Abdollah NA, Shafie NH, Yusof NM, Razak SR. Dual-specificity phosphatase 6 (DUSP6): a review of its molecular characteristics and clinical relevance in cancer. Cancer Biol Med. 2018; 15:14-28. https://doi.org/10.20892/j.issn.2095-3941.2017.0107. [PubMed]

50. James NE, Cantillo E, Oliver MT, Rowswell-Turner RB, Ribeiro JR, Kim KK, Chichester CO 3rd, DiSilvestro PA, Moore RG, Singh RK, Yano N, Zhao TC. HE4 suppresses the expression of osteopontin in mononuclear cells and compromises their cytotoxicity against ovarian cancer cells. Clin Exp Immunol. 2018; 193:327-40. https://doi.org/10.1111/cei.13153. [PubMed] 